\title{
Investigation of A Real-Time Driver Eye-Closeness for the Application of Drowsiness Detection
}

Muhammad Zubir bin Kamazlan', Wan Khairunizam', Abdul Hafiz Halin ${ }^{1}$, M. Rudzuan M. Nor', Azian Azamimi Abdullah², Norrima Mokhtar ${ }^{3}$

${ }^{1}$ Depart. of Mechatronic Eng., Faculty of Electrical Engineering Technology, University Malaysia Perlis, Malaysia

${ }^{2}$ Depart. of Biomedical Elec. Eng., Faculty of Electronic Engineering Technology, University Malaysia Perlis, Malaysia

${ }^{3}$ Department of Electrical Engineering, Faculty of Engineering, University of Malaya, Malaysia

${ }^{1}$ khairunizam@unimap.edu.my

\begin{abstract}
The increase in accident and death rates due to drowsiness while driving raises concerns to the community. An efficient solution is vital to ensure the safety of all drivers on the road. Most previous studies have analyzed drowsiness using head tilt, yawning, and eye condition. Face detection applied in drowsiness detection from previous research not included distances between subject and camera. The features used for eye detection required large storage and long-term process which are not applicable in a real-time system. This study uses Haar algorithm and analysis is performed based on the size of the region of interest for face detection. Eye monitoring uses facial landmark features and the evaluation is dependent on the width of the eye. The percentage of eye closure is used to describe the eyes as closed. This study only takes into account the normal rate of blinking eyes while driving because of the long-time constraints required for a person to be in a drowsy state. In this research, the Raspberry $\mathrm{Pi} 3 \mathrm{~B}+$ and Pi cameras are used as processing and vision devices. The highest accuracy of face detection achieved based on the ROI area at a distance of $80 \mathrm{~cm}$ is $98.33 \%$. The lowest difference between eye width and the intercanthal distance is $0.36 \%$. The overall normal eye blink rate while driving is in the range of the normal eye blink rate which does not exceed 20 blinks/min as reported by the previous researcher.
\end{abstract}

Keywords: Face detection, eye detection, drowsiness detection

\section{INTRODUCTION}

One of the potential applications of smart vehicle systems is the drowsy driver detection system [1]. Thus, the development of this system vital in preventing traffic accidents. This system works to measure the blink rate of the drivers based on eye-closeness. The eye condition contains critical information, and it is possible to determine a driver's level of drowsiness if such visual activity can be assessed [2].

Face detection is a primary component that requires a Pi camera that acts as a video sensor. The location of the eye should be determined before the eye's status can be specified using suitable image processing.

It has been confirmed in a U.S. Department of Transportation publication: "Only PERCLOS that are highly correlated with PVT blunders in and between subjects even though almost every innovation demonstrated the ability to diagnose drowsiness by detecting lapses in at least one subject or a subset of subjects" [3]. Increasing subjective sleepiness, decreasing efficiency, and the number of lapses in a visual reaction time task closely associated with PERCLOS values [4]. The proportion of time the eyelids cover at least $80 \%$ of the pupils is measured by PERCLOS [5].

PERCLOS is more dependable across drivers than EEG, blinks, and head position in the research since its algorithm was more than $90 \%$ precise in identifying deteriorated performance during alertness tasks as validated by Dinges et al. (1998) [6]. The eye conditions could be divided into a few sections relying on PERCLOS. Heartbeat rate, yawning, and head tilting are other terms that can calculate the level of drowsiness. However, this research only focuses on eyecloseness to determine the normal eye blink rate while driving due to limitations that required a long period for a person to fall in a drowsy state. 


\section{METHODS}

\subsection{Research Flow Chart}

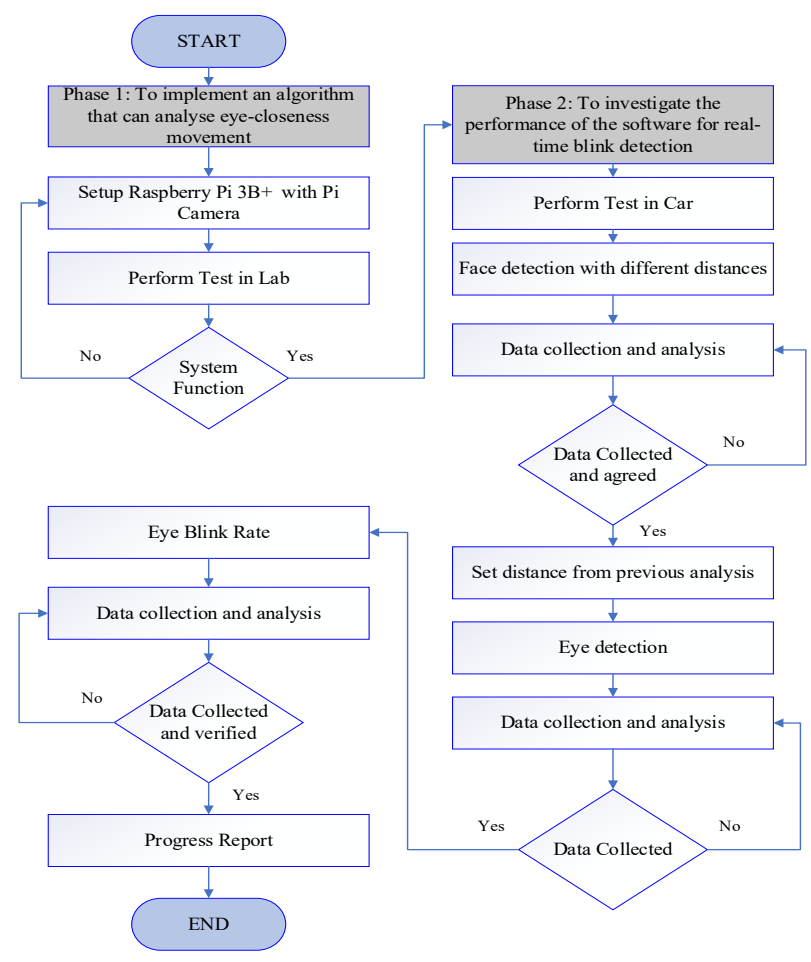

Fig. 1. Research flowchart

Fig. 1 shows the flow chart of the research. Phase \#1 is to design an algorithm that analyze the eye-closeness movement. The setup of software and hardware is performed in this phase. The system functionality is tested before proceeding to phase \#2. The aim of phase \#2 is to investigate the performance of the software for real-time eye blinking. This phase is separated in three parts, which are face detection, eye detection and eye blink rate. The experiments are carried out part by part.

\subsection{Software Setup}

Raspberry Pi 3 Model B+ chosen as a computer base to execute the program. 5 MP Raspberry Pi camera also needed as a visual device and an ultrasonic sensor used to measure the distance between subject and pi camera. OpenCVPython library is competent for this system to solve computer vision problems and obtain the required data. This library used the Haar Cascade Classifier (haarcascade_frontalface_default .xml) to detect the face in the frames. Dlib is a modern $\mathrm{C}++$ open-source library that implements numerous machine learning models and supports functions such as threading and networking. This library enables the use of shape_predictor_68_face_landmarks.dat to extract facial features effectively. The system functionality tested in the laboratory first before tested the real driver in the car.

\subsection{Experimental Setup}

Eight (8) subjects from ages 23 to 25 involved in the face and eye detection tests while only four subjects with more than one-year driving experience being tested in normal blink rate evaluation. The experiments conducted from 10 am to $12 \mathrm{pm}$ with sunny weather conditions. However, the dark-tinted car's window reduced the amount of light entering the car. Face and eye detection task conducted in a car at Universiti Malaysia Perlis. Normal Blink Rate experiment requires the subjects to drive on the highway from Pauh flyover to Universiti Malaysia Perlis as shown in Fig 2.

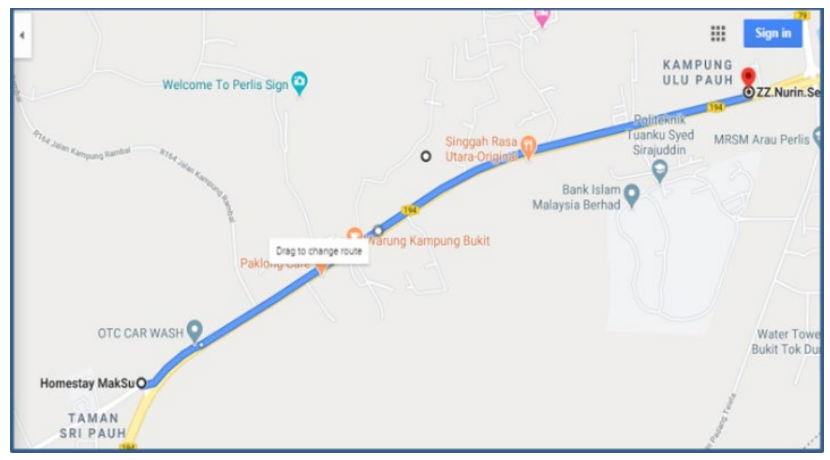

Fig. 2. Route used to measure blink rate while driving

\subsection{Face Detection}

The subjects placed in front of the camera as shown in Fig 3 with the value of $x=75 \mathrm{~cm}$ measured using the ultrasonic sensor in the car as the set distance between the seat and camera. The program executed to detect the face of the driver for one minute because the investigation of the system performance for the blink rate is based on every minute. The size of the rectangle as shown in Fig. 4 on the driver's face was stored as a measured value. The process repeated with a value of $x$ $=80 \mathrm{~cm}$ and $x=85 \mathrm{~cm}$ because the adjustable car seat has a $5 \mathrm{~cm}$ difference between each position. The program executed three times for each value of $x$ to obtain the average value. The average and standard deviation of the face area of five subjects were measured and is set as the reference. Three subjects were tested and analyzed based on these reference value. The reference value will be used to determine the 
accuracy from the further data obtained. If the data are not within the standard deviation of the reference value, the data is not accurate or acceptable.

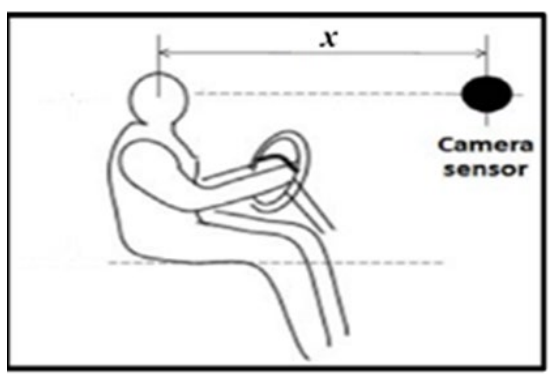

Fig. 3. Position of the subject in front of the camera

$$
\text { Area }=w \times h
$$

$P=\frac{k}{m} \times 100$

where:

P: Percentage Accuracy of the Area (\%)

$\mathrm{k}$ : number of data (area) within standard deviation of reference value

$\mathrm{m}$ : total of data sample (60)

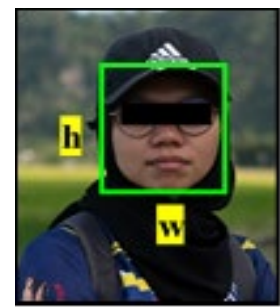

Fig 4. Face area based on ROI box

\subsection{Eye Detection}

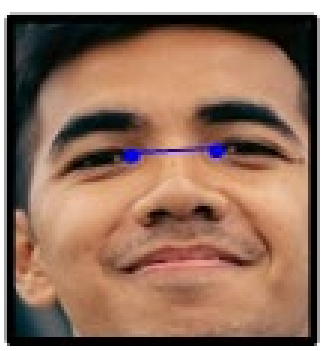

Fig. 5. Intercanthal distance

$$
\begin{aligned}
& \text { Euclidean distance, } d= \\
& \sqrt{(x 2-x 1)^{2}-(y 2-y 1)^{2}}
\end{aligned}
$$

$$
\begin{aligned}
& \text { intercanthal distance }=\text { width }(\text { right eye })= \\
& \text { width }(\text { left eye }) \\
& (p 39 \leftrightarrow p 42)=(p 36 \leftrightarrow p 39)=(p 42 \leftrightarrow p 45)
\end{aligned}
$$

The eye-detection proceeded using the $80 \mathrm{~cm}$ distance that has the most accuracy from face detection analysis. Facial landmarks were the process of tracking vital feature points on the face and had been used for distinguishing and portraying the distinctive regions of the face. The corners of each eye were located using the facial landmark predictor. The Euclidean distance between the points was determined. This task executed in one minute and repeated three times for each subject to determine the ability of the system to track the eye every minute. [7] stated that intercanthal distance in the average face is equal to the width of an eye. Thus, this task validates either the statement in [7] can be accepted or not.

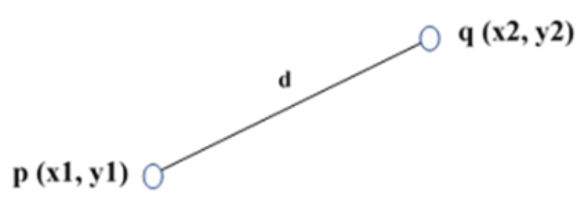

Fig. 6. Point axis

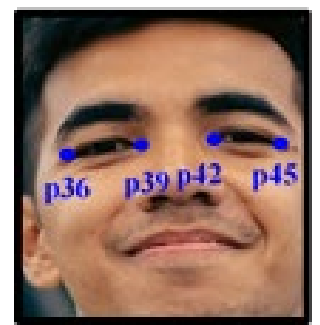

Fig. 7. Eye corner detection

\subsection{Normal Blink Rate}

This task performed within five minutes for each subject because the research analyses the blink rate for every minute. The Eye Aspect Ratio (EAR) from every subject while driving was recorded in this test. PERCLOS is the shortened form of eyelid closure over time [8]. PERCLOS (P80) applied to determine $80 \%$ the percentage closure of the eyes in the preliminary test. The value of $80 \%$ of eye closure set as threshold. The purpose of this task was to validate the normal eye blink rate while driving as mentioned in [9] that the normal eye blink rate is 15 to $20 \mathrm{blinks} / \mathrm{min}$ and the blink 
rate could decrease when the eyes focus on the work such as driving [10].

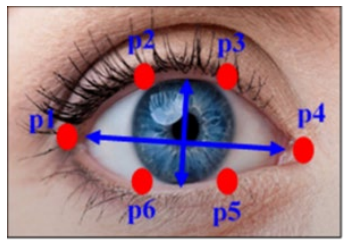

Fig. 8. Eye Aspect Ratio

$$
\begin{aligned}
& \text { EAR }=\frac{|| p 2-p 6\|+\| p 3-p 5||}{2\|p 1-p 4\|} \\
& \begin{aligned}
\text { EAR }(\text { both eye }) & =[\text { EAR (left eye }) \\
& + \text { EAR(right eye })] \div 2
\end{aligned}
\end{aligned}
$$

$$
\begin{aligned}
\text { Threshold }=[ & \max (E A R) \\
& -\min (E A R)] \times 0.2 \\
& +\min (E A R)
\end{aligned}
$$

\section{RESULTS AND DISCUSSIONS}

\subsection{Face Detection Analysis}

Table 1. ROI box average area target on different distances for 5 subjects

\begin{tabular}{|c|c|c|}
\hline Distance & $\begin{array}{c}\text { Reference Target } \\
\text { Area } \mathbf{( m m}^{\mathbf{2}} \mathbf{)}\end{array}$ & $\begin{array}{c}\text { Standard } \\
\text { Deviation }\end{array}$ \\
\hline $\mathbf{7 5} \mathbf{c m}$ & 5116 & 480 \\
\hline $\mathbf{8 0} \mathbf{c m}$ & 4376 & 217 \\
\hline $\mathbf{8 5} \mathbf{c m}$ & 3932 & 216 \\
\hline
\end{tabular}

Five (5) subjects are involved in assessing the average of the reference area of the ROI box for facial detection based on various distances. Three additional subjects are tested to assess the precision of the detection of the face. The data in this table is set as a reference for experiments of other subjects. If the data obtained in those tests are within the standard deviation, it is considered acceptable.
Table 2. ROI area for subject\#1

\begin{tabular}{|c|c|c|c|c|c|}
\hline $\begin{array}{c}\text { Distance } \\
\text { from } \\
\text { subject } \\
\text { to } \\
\text { camera }\end{array}$ & \multicolumn{2}{|c|}{ Reference Area } & \multicolumn{2}{c|}{ Obtained } & $\begin{array}{c}\text { Percentage } \\
\text { Accuracy } \\
\text { of the } \\
\text { Area (\%) }\end{array}$ \\
\hline & $\begin{array}{c}\text { Area } \\
\left(\mathrm{mm}^{2}\right)\end{array}$ & $\begin{array}{c}\text { Standard } \\
\text { Deviation }\end{array}$ & $\begin{array}{c}\text { Area } \\
\left(\mathrm{mm}^{2}\right)\end{array}$ & $\begin{array}{c}\text { Standard } \\
\text { Deviation }\end{array}$ & Note \\
\hline $75 \mathrm{~cm}$ & 5116 & 480 & 4789 & 122 & 81.67 \\
\hline $80 \mathrm{~cm}$ & 4376 & 217 & $\mathbf{4 2 5 3}$ & $\mathbf{9 0}$ & $\mathbf{9 0 . 0 0}$ \\
\hline $85 \mathrm{~cm}$ & 3932 & 216 & 3838 & 128 & 88.33 \\
\hline
\end{tabular}

Subject \#1 produces the average area of $4789 \mathrm{~mm}^{2}$ for the distance $75 \mathrm{~cm}, 4253 \mathrm{~mm}^{2}$ for the distance $80 \mathrm{~cm}$, and 3838 $\mathrm{mm}^{2}$ for the distance $85 \mathrm{~cm}$. The experiments are run three times for each distance and only the average with the lowest standard deviation is chosen. Percentage accuracy for distance $75 \mathrm{~cm}$ which is $81.67 \%$ measured using the equation 2 .

Table 3. ROI area for subject\#2

\begin{tabular}{|c|c|c|c|c|c|}
\hline $\begin{array}{c}\text { Distance } \\
\text { from } \\
\text { subject } \\
\text { to } \\
\text { camera }\end{array}$ & \multicolumn{2}{|c|}{ Reference Area } & \multicolumn{2}{|c|}{ Obtained } & $\begin{array}{c}\text { Percentage } \\
\text { Accuracy } \\
\text { of the Area } \\
(\%)\end{array}$ \\
\hline & $\begin{array}{c}\text { Area } \\
\left(\mathrm{mm}^{2}\right)\end{array}$ & $\begin{array}{c}\text { Standard } \\
\text { Deviation }\end{array}$ & $\begin{array}{c}\text { Area } \\
\left(\mathrm{mm}^{2}\right)\end{array}$ & $\begin{array}{c}\text { Standard } \\
\text { Deviation }\end{array}$ & \\
\hline $75 \mathrm{~cm}$ & 5116 & 480 & 5437 & 134 & 81.67 \\
\hline $80 \mathrm{~cm}$ & 4376 & 217 & $\mathbf{4 3 9 3}$ & $\mathbf{8 1}$ & $\mathbf{9 8 . 3 3}$ \\
\hline $85 \mathrm{~cm}$ & 3932 & 216 & 4071 & 109 & 83.33 \\
\hline
\end{tabular}

Subject \#2 produces the average area of $5437 \mathrm{~mm}^{2}$ for distance $75 \mathrm{~cm}, 4393 \mathrm{~mm}^{2}$ for distance $80 \mathrm{~cm}$, and 4071 $\mathrm{mm}^{2}$ for distance $85 \mathrm{~cm}$. The experiments are run three times for each distance and only the average with the lowest standard deviation is chosen. Percentage accuracy for distance $75 \mathrm{~cm}$ which is $81.67 \%$.

Table 4. ROI area for subject\#3

\begin{tabular}{|c|c|c|c|c|c|}
\hline $\begin{array}{c}\text { Distance } \\
\text { from } \\
\text { subject } \\
\text { to } \\
\text { camera }\end{array}$ & \multicolumn{2}{|c|}{ Reference Area } & \multicolumn{2}{|c|}{ Obtained } & $\begin{array}{c}\text { Percentage } \\
\text { Accuracy } \\
\text { of the Area } \\
(\%)\end{array}$ \\
\hline & $\begin{array}{c}\text { Area } \\
\left(\mathrm{mm}^{2}\right)\end{array}$ & $\begin{array}{c}\text { Standard } \\
\text { Deviation }\end{array}$ & $\begin{array}{c}\text { Area } \\
\left(\mathrm{mm}^{2}\right)\end{array}$ & $\begin{array}{c}\text { Standard } \\
\text { Deviation }\end{array}$ & \\
\hline $75 \mathrm{~cm}$ & 5116 & 480 & 4840 & 168 & 80.00 \\
\hline
\end{tabular}




\begin{tabular}{|c|c|c|c|c|c|}
\hline $80 \mathrm{~cm}$ & 4376 & 217 & $\mathbf{4 4 1 3}$ & $\mathbf{8 9}$ & $\mathbf{9 6 . 6 7}$ \\
\hline $85 \mathrm{~cm}$ & 3932 & 216 & 3743 & 91 & 86.67 \\
\hline
\end{tabular}

Subject \#3 produces the area of $4840 \mathrm{~mm}^{2}$ for distance 75 $\mathrm{cm}, 4413 \mathrm{~mm}^{2}$ for distance $80 \mathrm{~cm}$, and $3743 \mathrm{~mm}^{2}$ for distance $85 \mathrm{~cm}$. The information gathered for the most recent subject is obtained value and the reference area is the aim value.

The highest percentage accuracy among three subjects is for the distance of $80 \mathrm{~cm}$ and the lowest is at $75 \mathrm{~cm}$ distance. The error in percentage accuracy resulted from the area of ROI that varies out of the reference target standard deviation. The errors in the value occurred due to the complex background [11] and the lighting condition during the test [12].The distance with highest accuracy is better to be applied in further test because the facial landmark point is depend on the ROI area. Thus, the highest accuracy will ensure that the position of facial landmark have the lowest variation.

\subsection{Eye Detection Analysis}

This task is performed with a distance of $80 \mathrm{~cm}$ from the camera to the subject because it has the highest accuracy of face detection. Table 5 records the eye width and intercanthal distance for each subject. Percentage of different measured the inequality between the average width of both eye and the intercanthal distance. As we can see, the lowest percentage difference is from subject 1 while others have a large percentage difference between eye width and intercanthal distance. Thus, only subject \#1 fulfilled the statement in [7] that the eye width is equal to intercanthal distance on the average face. The other subject may have a broad range of measurements between eye width and intercanthal distances due to the low resolution of the vision device used.

Table 5. Eye width and intercanthal distance

\begin{tabular}{|c|c|c|c|}
\hline Subject & $\begin{array}{c}\text { Average eye } \\
\text { width for } \\
\text { both eye } \\
(\mathrm{mm})\end{array}$ & $\begin{array}{c}\text { Intercanthal } \\
\text { Distance }(\mathrm{mm})\end{array}$ & $\begin{array}{c}\text { Percentage of } \\
\text { different }\end{array}$ \\
\hline$\# 1$ & 9.945 & 9.909 & 0.36 \\
\hline$\# 2$ & 9.989 & 15.771 & 36.66 \\
\hline$\# 3$ & 9.048 & 15.614 & 36.05 \\
\hline$\# 4$ & 10.58 & 16.695 & 36.63 \\
\hline$\# 5$ & 10.85 & 16.968 & 36.05 \\
\hline$\# 6$ & 9.958 & 16.998 & 41.42 \\
\hline$\# 7$ & 10.069 & 17.362 & 42.01 \\
\hline$\# 8$ & 9.045 & 15.997 & 43.46 \\
\hline
\end{tabular}

Fig 9 shows that only subject \#1 has the smallest difference between eye width and intercanthal distance while the other has a large gap between both values. The eye width in the average face is not equal to the intercanthal distance as mentioned in [7] since seven over eight-person have a large percentage difference between those values.

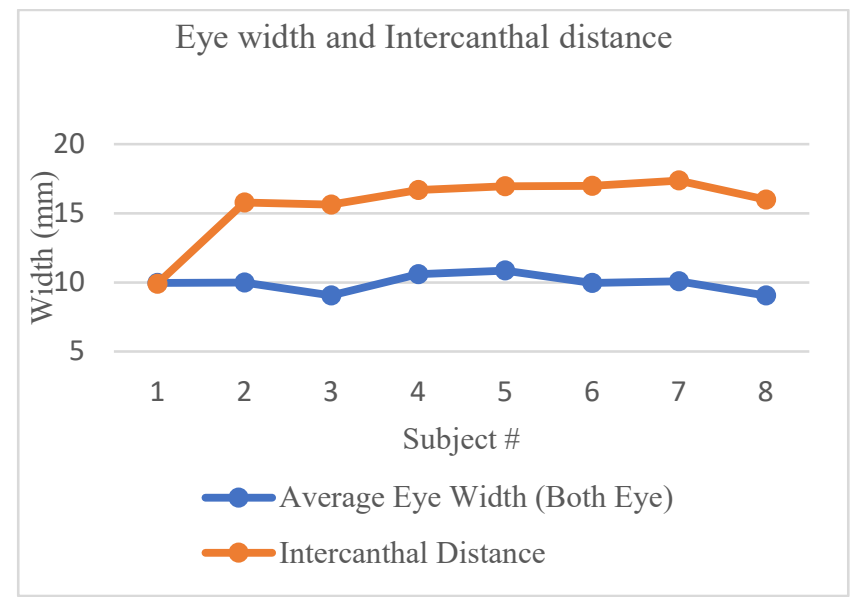

Fig. 9. Eye width and intercanthal distance

\subsection{Eye Blink Rate Analysis}

Table 6. Eye blink for subject \#1

\begin{tabular}{|c|c|}
\hline Time(minute) & Blink rate \\
\hline $1^{\text {st }}$ & 4 blink $/$ min \\
\hline $2^{\text {nd }}$ & 5 blink $/$ min \\
\hline $3^{\text {rd }}$ & 6 blink $/$ min \\
\hline $4^{\text {th }}$ & 4 blink $/$ min \\
\hline $5^{\text {th }}$ & 5 blink $/$ min \\
\hline
\end{tabular}

The normal eye blink rate for subject \#1 for five minutes is listed in Table 6. Fig 10 shows the EAR plotted for subject $\# 1$. The threshold of the EAR for this subject 0.1814 determined by the minimum and maximum value of EAR which are 0.127 and 0.399 . The value below the threshold is classified as a blink. The calculation of the threshold can be referred to equation 8.0. 


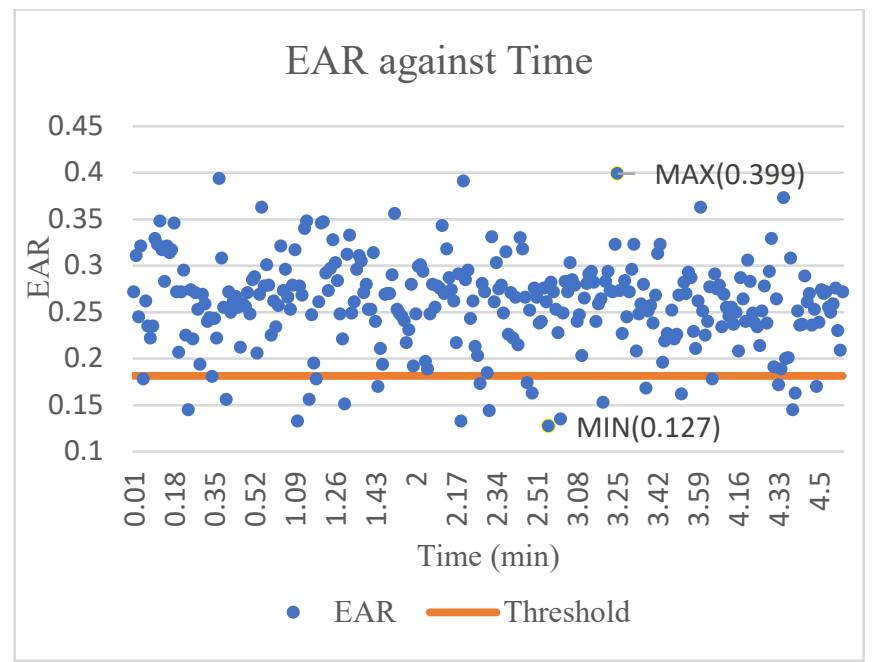

Fig. 10. The EAR for Subject \#1

Table 7. Eye blink for subject \#2

\begin{tabular}{|c|c|}
\hline Time(minute) & Blink rate \\
\hline 1st & 5 blink $/ \mathrm{min}$ \\
\hline 2nd & $4 \mathrm{blink} / \mathrm{min}$ \\
\hline 3rd & $6 \mathrm{blink} / \mathrm{min}$ \\
\hline $4 \mathrm{th}$ & $4 \mathrm{blink} / \mathrm{min}$ \\
\hline $5 \mathrm{th}$ & $2 \mathrm{blink} / \mathrm{min}$ \\
\hline
\end{tabular}

Table 7 indicates five minutes of the normal eye blink rate for subject \#2. The EAR for subject \#2 is shown in Fig 11. The minimum and maximum values for EAR are 0.142 and 0.415 were used to determine the threshold value of 0.1966 . The threshold is the value where $80 \%$ of the eyes are closed.

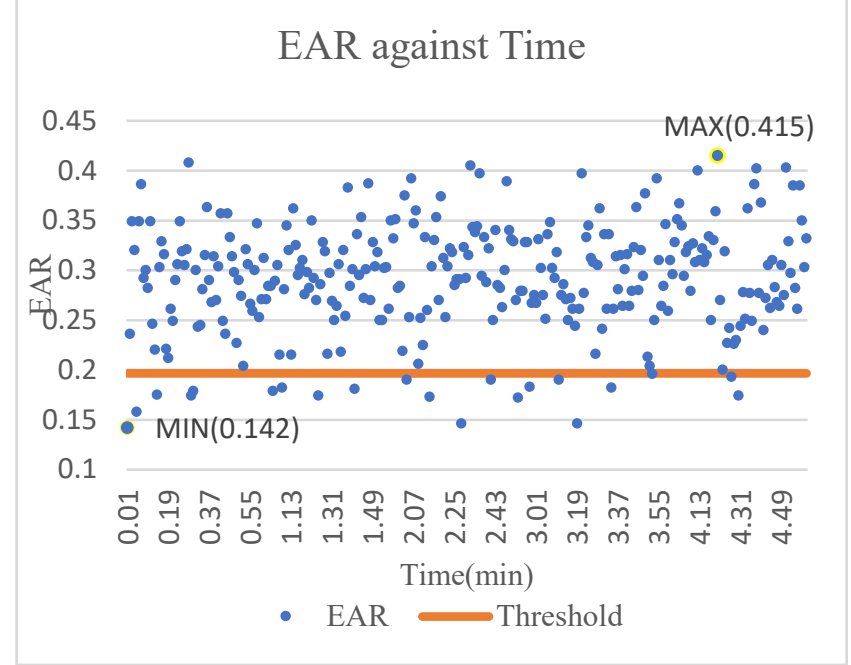

Fig. 11. The EAR for Subject \#2
Table 8. Eye blink for subject \#3

\begin{tabular}{|c|c|}
\hline Time(minute) & Blink rate \\
\hline 1st & $9 \mathrm{blink} / \mathrm{min}$ \\
\hline 2nd & $5 \mathrm{blink} / \mathrm{min}$ \\
\hline 3rd & $11 \mathrm{blink} / \mathrm{min}$ \\
\hline 4th & $10 \mathrm{blink} / \mathrm{min}$ \\
\hline 5 th & $15 \mathrm{blink} / \mathrm{min}$ \\
\hline
\end{tabular}

The normal eye blink rate for subject 3 for five minutes is listed in Table 11. Fig 12 shows the EAR plotted for subject \#3. The EAR threshold for this subject 0.2146 is determined by the minimum and maximum EAR values of 0.138 and 0.521 . The eyes will be considered as close if the eyelids covered more than $80 \%$ or less than 0.2146 of the EAR.

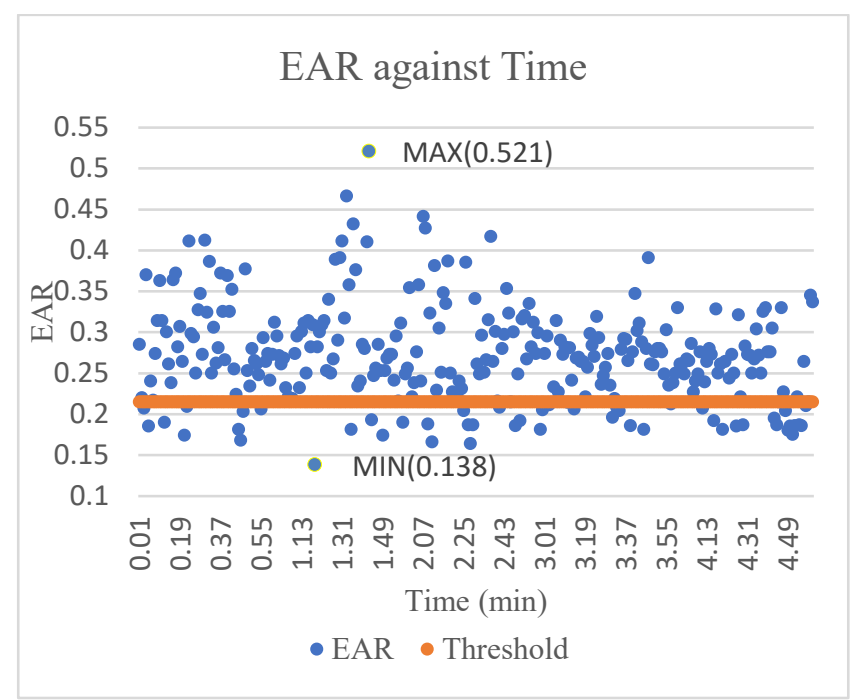

Fig 12. EAR for Subject \#3

Overall eye blink rate for four subjects are not exceeding 20 blinks per minute. It is as mention in [9] and [10] that the normal eye blink rate for an average person is not more than 20 blinks per minute. There are differences in the blink rate between subject \#3 and subject \#1, subject \#2 as well as subject \#4. The lower blink rate of subject \#1, subject \#2, and subject \#4 due to focus state while driving as referred to [9] and [10]. Subject \#3 may have a higher blinking rate because of the cold environment due to the air conditioner in the car. The rise of the blink rate can increase eye temperature [13]. 


\section{CONCLUSIONS}

The Eye-Closeness system is a functional system to use for drowsiness detection applications. The features applied in this system is dependable to identify the drowsy condition. This research has proven that most accuracy of face detection is above $80 \%$ and the highest reading achieved is $98.33 \%$. The error occurred only as a result of the complex background and unsteady lighting while performing the test. Seven over eight-persons have a broad range of measurements between eye width and intercanthal distances due to the low resolution of the hardware used. Throughout the whole experiment, the algorithm implemented is functional to analyse the eye-closeness movement. System performance is reliable because all four subjects tested for normal eye blink rate while driving is within the normal blink rate that is below $20 \mathrm{blinks} / \mathrm{min}$ as indicated in the previous research by Tereza Soukupov' [9]. The safety of the driver and other road users should be concerned. Hence, the use of this system can prevent accidents caused by drowsiness.

\section{REFERENCES}

[1] E. Vural, M. Cetin, A. Ereil, G. Littlewort, M. Bartlett, and J. Movellan, "Drowsy driver detection through facial movement analysis," Lect. Notes Comput. Sci. (including Subser. Lect. Notes Artif. Intell. Lect. Notes Bioinformatics), vol. 4796 LNCS, no. November, pp. 6-18, 2007.

[2] P. R. Tabrizi and R. A. Zoroofi, "Drowsiness detection based on brightness and numeral features of eye image," IIH-MSP 2009 - 2009 5th Int. Conf. Intell. Inf. Hiding Multimed. Signal Process., pp. 1310-1313, 2009.

[3] D. Sommer and D. Edwards, "PERCLOS: An Alertness Measure of the Past," no. October, 2017.

[4] G. Marquart, C. Cabrall, and J. de Winter, "Review of Eyerelated Measures of Drivers' Mental Workload," Procedia Manuf., vol. 3, no. Ahfe, pp. 2854-2861, 2015.

[5] S. Vitabile, A. De Paola, and F. Sorbello, "Bright pupil detection in an embedded, real-time drowsiness monitoring system," Proc. - Int. Conf. Adv. Inf. Netw. Appl. AINA, pp. 661-668, 2010.

[6] A. D. McDonald, J. D. Lee, C. Schwarz, and T. L. Brown, “A contextual and temporal algorithm for driver drowsiness detection," Accid. Anal. Prev., vol. 113, no. January, pp. 2537, 2018.

[7] J. van L. Gerhard Goos, Juris Hartmanis, Audio- andVideoBased Biometric Person Authentication. 2001.

[8] J. J. Yan, H. H. Kuo, Y. F. Lin, and T. L. Liao, "Real-time driver drowsiness detection system based on PERCLOS and grayscale image processing," Proc. - 2016 IEEE Int. Symp. Comput. Consum. Control. IS3C 2016, pp. 243-246, 2016.

[9] M. Perception and C. Technical, "Eye-Blink Detection Using Facial Landmarks," 2016.
[10] Z. A. Haq, "Eye-Blink rate detection for fatigue determination," no. March, 2018.

[11] V. Singh, V. Shokeen, and B. Singh, "Face Detection By Haar Cascade Classifier With Simple And Complex Backgrounds Images Using Opencv Implementation," Int. J. Adv. Technol. Eng. Sci., vol. 1, no. 12, pp. 33-38, 2013.

[12] M. Rezaei and R. Klette, Driver Drowsiness Detection. 2017.

[13] D. B. Gurung, K. C. Gokul, and P. R. Adhikary, "Mathematical model of thermal effects of blinking in human eye," Int. J. Biomath., vol. 9, no. 1, 2016. 